\title{
Políticas públicas de desenvolvimento
}

\author{
Public development policies \\ Políticas de desarrollo público
}

\section{Resumo}

Com o fim da Segunda Guerra mundial e a dinâmica da economia, os países entraram na corrida pela disputa dentro do novo modelo globalizado. Com isso, se expandiu uma sociedade urbano-industrial, com necessidades e carecimentos politizados que se transformaram em questões públicas, necessitando de maiores intervenções do Estado, principalmente pela integração à nova ordem econômica mundial, dando ênfase na necessidade de políticas públicas para que o desenvolvimento fosse mais coeso e igualitário. Dentro desse contexto, o presente artigo é uma pesquisa exploratória bibliográfica do tipo qualitativa que objetiva o entendimento da necessidade de políticas públicas para a promoção do desenvolvimento no Brasil trazendo ações públicas importantes nesse processo como a criação das superintendências SUDENE, SUDECO, SUDESUL, SUDAM, além de base para conhecimento de termos como: desenvolvimento, espaço, região, desenvolvimento regional e desenvolvimento local. O arcabouço teórico se estrutura em autores como: Celso Furtado, Henri Lefebvre, David Harvey, dentre outros que foram encontrados nos bancos de dados: Scopus, Web of Science e Scielo. Como resultado entende-se que as políticas públicas vêm sendo discutida sua necessidade ao longo dos anos, e se mostram necessárias, mas ainda faltam muitos aprimoramentos.

Palavras-chave: Políticas públicas; Desenvolvimento regional; Disparidade regional.

\begin{abstract}
With the end of World War II and the dynamics of the economy, countries entered the race to compete within the new globalized model. With this, an urban-industrial society has expanded, with politicized needs and needs that have become public issues, requiring greater State interventions, especially for integration into the new world economic order, emphasizing the need for public policies for development be more cohesive and egalitarian. Within this context, this article is a qualitative bibliographic exploratory research that aims to understand the need for public policies to promote development in Brazil, bringing important public actions in this process, such as the creation of superintendencies SUDENE, SUDECO, SUDESUL, SUDAM, as well as a basis for knowledge of terms such as: development, space, region, regional development and local development. The theoretical framework is structured in authors such as: Celso Furtado, Henri Lefebvre, David Harvey, among others that were found in the databases: Scopus, Web of Science and Scielo. As a result, it is understood that public policies have been discussed over the years, and are shown to be necessary, but there are still many improvements to be made.
\end{abstract}

Keywords: Public policy; Regional development; Regional disparity.

\section{Resumen}

Con el fin de la Segunda Guerra Mundial y la dinámica de la economía, los países entraron en la carrera por competir dentro del nuevo modelo globalizado. Con esto, se ha expandido una sociedad urbano-industrial, con necesidades politizadas y necesidades que se han convertido en asuntos públicos, requiriendo mayores intervenciones del Estado, especialmente para la integración al nuevo orden económico mundial, enfatizando la necesidad de que las políticas públicas para el desarrollo sean más cohesionadas e igualitarias. . En este contexto, este artículo es una investigación 
exploratoria bibliográfica cualitativa que tiene como objetivo comprender la necesidad de políticas públicas para promover el desarrollo en Brasil, trayendo importantes acciones públicas en este proceso, como la creación de las superintendencias SUDENE, SUDECO, SUDESUL, SUDAM, como así como una base para el conocimiento de términos como: desarrollo, espacio, región, desarrollo regional y desarrollo local. El marco teórico está estructurado en autores como: Celso Furtado, Henri Lefebvre, David Harvey, entre otros que se encontraron en las bases de datos: Scopus, Web of Science y Scielo. Como resultado, se entiende que las políticas públicas se han discutido a lo largo de los años y se muestran necesarias, pero aún quedan muchas mejoras por hacer.

Palabras clave: Políticas públicas; Desarrollo regional; Disparidad regional.

\section{Introdução}

A problemática do elevado nível de desigualdade regional no país já vem sendo discutida com frequência desde meados do século XX. O tema das políticas públicas e questões de desenvolvimento regional são preocupações presentes na realidade brasileira desde a década de 1930. Vazios territoriais e desigualdades regionais já eram fatores preponderantes desde essa época. (Cavalcante, 2018).

Porém todo esse contexto se agravou após a Segunda Guerra Mundial, onde a competitividade intensificou ainda mais esses problemas que já existiam em escalas menores. Com isso, houve maior necessidade de ação do Estado para solucionálos, afinal, "o desenvolvimento ocorre de forma desigual e uma vez iniciado em determinados pontos, tem a característica de fortalecer as regiões mais dinâmicas em detrimento das menos dinâmicas.” (Correa, Rogério \& Kist, 2019)

Passando por um breve resumo podem ser citadas ações que mostram essas intervenções, como por exemplo: durante as décadas de 1950 e 1970 políticas regionais estiveram no centro da agenda nacional, como a criação das superintendências do nordeste, Centro Oeste e do Sul. Mas nas décadas de 1980 e 1990 essas questões perderam forças no cenário nacional. E no ano de 2007 foi institucionalizada a Política Nacional de Desenvolvimento Regional (PNDR).

A PNDR trouxe em sua estrutura novas discussões com bases renovadas, princípios e diretrizes para nortear o país às soluções de problemas ligados ao desenvolvimento. Houve então a necessidade de nova reformulação que resultou então na PNDR II.

Neste artigo objetivou-se entender as mudanças na economia do pós segunda guerra que influenciou no processo de desenvolvimento com disparidades regionais no País, e como o Estado se utilizou de políticas públicas para tentar o direcionamento do Desenvolvimento Regional no Brasil.

\section{Metodologia}

Metodologia é onde os autores demonstram o caminho que foi percorrido no estudo para responder questionamentos que os levaram a concepção pesquisa. O presente artigo busca entendimento maior sobre o tema Políticas Públicas e Desenvolvimento Regional com diálogos entre autores do campo desse conhecimento e foi estruturado em quatro partes principais. (De Andrade Carneiro et al, 2020)

A argumentação surgiu da pesquisa exploratória que de acordo com Gil (2008), habitualmente envolve levantamento bibliográfico e/ou documental, o autor ainda explica que: "Pesquisas exploratórias são desenvolvidas com o objetivo de proporcionar visão geral, de tipo aproximativo, acerca de determinado fato”. (Gil, 2008, p.27).

Inicialmente é explicada a definição de políticas públicas. Logo depois é feita uma explanação sobre desenvolvimento, e as diversas formas de enxergar e definir esse termo pela visão de autores de importância no tema, como por exemplo Celso Furtado. A terceira parte é a revisão exploratória sobre desenvolvimento local e regional, e fatores que são considerados para medir o desenvolvimento. E por fim são descritas ações de políticas públicas importantes que tiveram como finalidade promover Desenvolvimento Regional com menor disparidade e com mais coesão no Brasil a partir da década de 1960 e finalizando na segunda versão da Política Nacional de Desenvolvimento Regional (PNDR II). 
Para a pesquisa de exploração bibliográfica foram selecionadas e coletadas fontes como livros, monografias, teses, artigos e dissertações publicados em periódicos em bases de dados, principalmente Scopus, Web of Science e Scielo.

Para buscas nas bases de pesquisas foram utilizados descritores-chaves que melhor abarcavam a pesquisa do tipo: Política pública, Desenvolvimento Regional, Desenvolvimento Local, Território, Governança, SUDENE, SUDECO, SUDESUL, SUDAM, Disparidade Regional, Coesão Regional.

Dentro do tema geral Desenvolvimento Regional, Local e definições pertinentes aos termos foram referenciadas e estudadas 19 fontes. Já no tema geral de Políticas Públicas e de Desenvolvimento, definições e políticas nacionais foram 11 fontes. Esses autores deram embasamento para este artigo.

\section{Políticas Públicas}

É importante entender que o conceito de políticas públicas pode abarcar diversas definições e concepções.

Para Teixeira (2002, p.2) o conceito de políticas públicas é definido da seguinte maneira: "são diretrizes, princípios norteadores de ação do poder público; regras e procedimentos para as relações entre poder público e sociedade, mediações entre atores da sociedade e do Estado". Sendo assim pode ser descrito como uma forma de poder político onde envolve a distribuição e redistribuição do poder dentro da sociedade.

Partindo do pensamento de Souza (2009, p.24), políticas públicas podem ser conceituadas como "um fenômeno social e histórico que expressa os interesses e necessidades de diversos sujeitos sociais, através do exercício do poder, e do processo de tomada de decisões baseado nos valores presentes na sociedade".

Radaelli $(2013$, p. 3) traz a seguinte definição: "ações específicas do Estado num processo de consolidação de um projeto de sociedade".

Por sua vez, Castro e Oliveira (2014, p.22) entendem como políticas públicas "o conjunto de políticas, programas e ações do Estado, diretamente ou por meio de delegação, com objetivo de enfrentar desafios e aproveitar oportunidades de interesse coletivo".

Paula e Almeida (2020, p.1059) descrevem políticas públicas sendo "tudo o que os governos decidem, fazer ou deixar, isto é, a arte de governar é realizar o bem público, a fim de solucionar os problemas sociais"

No texto dessa pesquisa o termo será retratado como sendo sistemas de ações dos governantes para produzir efeitos específicos com a finalidade de responderem às demandas da sociedade.

\subsection{Desenvolvimento}

A definição de desenvolvimento passou por diversos momentos históricos. Tem como marco principal, do início dos principais debates, o fim da Segunda Guerra Mundial e esses debates adviriam da necessidade de melhoria nas condições de vida das pessoas.

Enriquez (2013), separa os principais pensadores de desenvolvimento em três grupos principais: I) neomarxistas; II) desenvolvimento sustentável e III) desenvolvimento como crescimento.

As definições são vastas, como por exemplo Escolas Clássicas e Neoclássicas da economia consideram que crescimento e desenvolvimento são tratados como sinônimos, como conceituado por Furtado em 1961: "desenvolvimento é, basicamente, aumento do fluxo de renda real, isto é, incremento na quantidade de bens e serviços por unidade de tempo à disposição de determinada coletividade". Ou seja, trata desenvolvimento como crescimento. (Furtado, 1961, p.115-116).

Na mesma linha de pensamento, Milone (1998) entende a caracterização do desenvolvimento como variáveis de crescimento econômico: renda, renda per capita; e sociais: redução de pobreza, níveis de saúde, desigualdade, nutrição, educação, moradia e transporte. 
Por outro lado, escolas que são por influência Marxista se embasam na teoria que crescimento é uma das condições do desenvolvimento, porém não suficiente para quantificar, é necessário que se associe à outras variáveis de análise qualitativas, e como exemplo dessa corrente tem os autores Raul Prebisch e Celso Furtado. (Oliveira, 2002).

Reyes (2001), propõe desenvolvimento baseado em três pilares principais: social, econômico e político. Esse embasamento se fundamenta no desenvolvimento sustentável, o qual é descrito abaixo para melhor ilustrar, retirado da tradução do artigo de Reyes:

O termo desenvolvimento é entendido como uma condição social dentro de uma nação, em que as necessidades autênticas de sua população são satisfeitas com o uso racional e sustentável dos recursos e sistemas naturais. Esta utilização dos recursos naturais é baseada em uma tecnologia, que respeita as características culturais da população de um determinado país. Esta definição geral de desenvolvimento inclui a especificação de que grupos sociais têm acesso a organizações, serviços básicos, como educação, habitação, serviços de saúde e nutrição e, acima de tudo, que suas culturas e tradições sejam respeitadas no quadro social de um determinado país. Em termos econômicos, a definição acima mencionada indica que para a população de um país, há oportunidades de emprego, satisfação - em menos das necessidades básicas, e o alcance de uma taxa positiva de distribuição e redistribuição da riqueza nacional. Em um sentido político, esta definição enfatiza que os sistemas governamentais têm legitimidade não só nos termos da lei, mas também em termos de benefícios sociais para a maioria da população. (Reyes, 2001, p.1).

Nessa pesquisa o termo desenvolvimento será tratado nas seguintes variáveis: social, econômica e ambiental (os três pilares de desenvolvimento sustentável). Sendo assim, o desenvolvimento não será entendido apenas como crescimento econômico, esse deve ser associado a questões de melhoria social e preocupação ambiental.

Afinal, desenvolvimento é um processo de mudanças complexas, dentro das ordens econômica, humana, política e social. Ou seja, incrementos positivos na renda que satisfazem as necessidades diversas da sociedade, como por exemplo: saúde, educação, transporte, alimentação, meio ambiente, dentre outros.

\subsubsection{Desenvolvimento Regional e Local}

Para os autores Corrêa, Silveira e Kist (2019), praticamente não há diferenciação na conceituação de desenvolvimento de uma nação e desenvolvimento de uma região, porém as explicações podem se diferenciar, seja por motivos de escala, características socioespaciais, e da diferença que pode haver na historicidade dos territórios, até mesmo nas questões de autonomia administrativa.

Para pensar em desenvolvimento regional é necessário, mesmo que de forma mais sintética, o entendimento de região que também faz ligação com o termo de espaço que será o primeiro a ser definido.

Inicialmente ao se pensar em espaço, David Harvey concluiu que a definição do termo é de extrema complicação, chegou-se a tal conclusão através da ideia de que a concepção de espaço não pode ser a ela conferido significado caso seja isolado de outras concepções. (Harvey, 1993).

Existe ainda a subdivisão dentro da definição espaço de acordo a Harvey (1973). Tem-se o espaço absoluto que tem sua existência tomada de forma independente da matéria circundante, mais conhecido por ser tratado como compartimento que se depositam ou dispõem coisas.

Quando se trata de relação entre objetos onde há interação entre coisas, se trata do espaço relativo. Existe ainda o espaço relacional, que é aquele contido nas coisas, onde um objeto existe somente na medida que contém relações com outros objetos. (Harvey, 1973).

É preciso dar enfoque no fato de que território não pode ser considerado o mesmo que espaço. Território está relacionado à dimensão espacial. Há duas linhas principais de definição que relacionam espaço e território. De um lado há aqueles que consideram que o espaço seja a primeira natureza do território, ou seja, que é antecessor onde a partir do espaço 
dado, o território se torna uma produção social a partir disso. De outro lado há o pensamento contrário a essa explicação, onde o espaço não antecede ao território, já que se considera que o espaço é também socialmente produzido, diferenciando o território apenas por este repousar na dimensão política do espaço construído. (Lefebvre, 1991).

Ainda sobre território, esse pode ser descrito como espaço geográfico onde há interação entre um sistema de ações e um sistema de objetos, e não se pode esquecer de mencionar outra dimensão que não pode ficar de fora dessa definição, sobre território, que é a política afinal é o Estado que administra o território na esfera de nação.

Abordar o território leva à necessidade de se descrever governança que para Dallabrida (2010) esse termo se refere às ações ou iniciativas que têm papel de expressar a capacidade que as sociedades organizadas territorialmente possuem de gerir assuntos públicos partindo do envolvimento cooperativo e conjunto de fatores econômicos, sociais e institucionais.

Com enfoque em Região, sua descrição é considerada como a definição mais problemática dos conceitos da economia, principalmente por ser fundamental para os geógrafos e muito controvertida no domínio da própria geografia. (Haesbaert, 2005, 2010). Os parágrafos seguintes demonstram a visão de autores a respeito desse termo.

Pozenato (2001) descreve região na visão da geografia da seguinte maneira:

A ideia de região como um espaço natural talvez tenha surgido a partir de sua utilização pela Geografia. A Geografia Física circunscreve territórios em função da paisagem, como se dizia antigamente, ou seja, da Meteorologia, da Hidrologia, da Topografia, da vegetação etc. A Geografia Humana define os espaços regionais também com critérios objetivos, fornecidos pela História, pela Etnografia, pela Linguística, pela Economia e pela Sociologia. Como nem sempre esses critérios coincidem, é possível falar de região histórica, região cultural, região econômica e assim por diante, com fronteiras distintas no mesmo território físico. (Pozenato, 2001, p.590).

Pelo descrito dentro da geografia, região se aproxima mais de questões de espaço e território. Uma delimitação mais voltada para delimitações do espaço físico.

Lencioni (1999), afirmou que região é um espaço onde características socioculturais e físicas são homogêneas, e fruto de histórias que fez deste espaço o lugar de pessoas enraizadas ali. Esse conceito dá características mais sociais à definição. (Lencioni, 1999).

Já Ribeiro (2004) expressa a região como sendo uma área que articula ordens e comando com cooperação, conflitos locais e cotidiano. Corresponde ao extenso de uma sociedade com relações da sociedade-natureza incluindo organização social, cultura e decisão política. (Ribeiro, 2004).

Limonad (2004) embasado na Geografia crítica definiu que região primeiramente precisa ser entendida como uma construção social que se destina a atender interesses políticos precisos. Dentro desse contexto onde todos os agentes são portadores de nacionalidade em sua intervenção no espaço, sendo então produto do pensamento social, com práticas que podem ser tanto hegemônicas quanto contra hegemônicas.

Além disso, a região pode ser construída "a partir da ação de distintos atores/agentes/sujeitos em múltiplas escalas articuladas que de certa forma encontram rebatimento em práticas e processos socioespaciais histórica e geograficamente localizados". (Limonad, 2004, p.57-58).

Ainda há base de definição que descreve região como um contexto amplo de relações, podendo elas serem econômicas, sociais, políticas, entre outras. Nesse mesmo sentido, ainda se pode complementar como sendo espaço onde interliga dialeticamente formas especiais de reprodução de capital. (Oliveira, 1981).

Quando se fala no contexto de desenvolvimento regional, pode-se entender região como parte da totalidade, sendo que essa totalidade não se encaixa como lógica ou mesmo harmônica, mas uma totalidade da concepção de formação econômicosocial, de forma mais histórica. Sendo assim, a condição de região não será tratada como associação atribuída apenas às condições naturais ou físicas. 
Já passado por definições de desenvolvimento, espaço e região, e entendido estes termos, os parágrafos seguintes foram dedicados ao entendimento de desenvolvimento regional e local segundo perspectivas de autores conhecidos.

Quando se aborda desenvolvimento regional de forma recente (nos últimos 30 anos), faz-se alusão de forma direta ou indireta à Celso Furtado. Afinal o autor faz uma análise perspicaz da lógica econômica à qual o Brasil tem sido governado e as repercussões que essa forma trouxe ao território. Quando se trata de Brasil, Furtado (1999) apresenta o seguinte:

Como somos um país com fronteiras que se deslocam permanentemente dentro do próprio território, nosso conceito de região é necessariamente dinâmico. Mas essa consciência de unidade nacional, dentro de um espaço que se expande, coexiste com o senso de identidade que se definiu historicamente em cada região particular. A identidade do brasileiro tem raízes em sua inserção regional (Furtado, 1999, p.47).

Ao se pensar em desenvolvimento local, para fins de comparação com definição de desenvolvimento regional, podese embasar no descrito por Bellingieri (2017):

Cabe destacar que desenvolvimento local não é sinônimo de desenvolvimento municipal. O desenvolvimento local, conceito identificado com o paradigma do desenvolvimento endógeno, não se refere a uma escala geográfica determinada, mas, sim, a um território socialmente construído, podendo, portanto, remeter tanto ao desenvolvimento de uma cidade quanto ao de um grupo de cidades ou ao de uma região, embora muitas vezes acabe sendo utilizado como sinônimo de desenvolvimento de cidades. (Bellingieri, 2017, p.8).

Para Oliveira, Silva e Lovato (2014) Desenvolvimento Local é a dinâmica que relaciona o conjunto de fatores como social, econômico, cultural e política, em que são atuantes numa demarcação de território por possuir características próprias qualitativas.

Nesse sentido, desenvolvimento regional será aqui tratado como sendo melhorias nos três pilares principais: social, econômico e ambiental, de um determinado recorte a ser analisado. Vale ressaltar que essas melhorias não se encaixam apenas em quantitativas, mas qualitativas também.

\subsection{Políticas Públicas Nacionais de Desenvolvimento}

Com a crise mundial em 1973 e o agravamento pelo choque do petróleo, o modelo keynesiano/fordista passou por transição para o novo modelo de regime de acumulação. Esse novo modelo se embasou na flexibilização de processos de trabalho, de capital, dos produtos e até mesmo do mercado de trabalho. (Harvey, 1993).

Com o colapso do modelo keynesiano/fordista colocou em queda o Estado desenvolvimentista, que havia ganhado força no período de reabilitação do pós Segunda Guerra Mundial. Esse novo modelo que veio em substituição resultou na necessidade de profundas mudanças no sistema político e na reorganização do mercado mundial. (Cargin, 2011).

Diante da nova organização da economia, que ia em direção ao modelo de globalização, o novo conjunto de medidas desse padrão era de facilitar o trânsito das empresas com investimentos em infraestrutura e logística. Com isso, em países da América Latina foi disseminado a austeridade fiscal e econômica a fim de expandir a nova economia.

Nesse novo cenário houve desvalorização do planejamento territorial em escalas nacionais. O Brasil não estando preparado para assumir essas novas funções impostas pelo mercado, sucumbiu à nova onda de privatizações e desregulamentações em favor do Estado mínimo, e assim questionavam a existência de instituições que tratavam do planejamento territorial. (Azzoni, 2007)

As barreiras se tornaram porosas para a entrada de empresas, que encontraram no Brasil o território adequado para suas instalações. Essa distribuição de empresas se instaurou de forma polarizada, em que regiões do país se beneficiaram mais que outras, em que as menos favorecidas foram as regiões Norte e Nordeste. 
De maneira geral, esse quadro de mudanças no sistema global trouxe consequências que colocou a questão regional em pauta, consequências essas principalmente em relação às disparidades regionais. Pois a possibilidade de êxito de uma região era medida pela capacidade desta se inserir no mercado globalizado. Com isso o debate e a necessidade de se pensar em questões de política públicas de desenvolvimento regional começaram a ser realidade, principalmente na década de 1990. (Vainer, 2007)

Essas desigualdades fazem parte de uma dimensão do desenvolvimento, pois estão inseridas no modelo de produção, e suas consequências podem ser visualizadas no território por meio das diferenças que se instalaram na estrutura econômica e social dos lugares. (Smith, 1988; Soja, 1993).

O Estado em seu papel de preocupação com a totalidade de um território não pode permitir e aceitar o agravamento em níveis elevados dessas desigualdades, pois o aprofundamento destas exclui populações de porções de territórios dos benefícios que o desenvolvimento carrega. Eles podem ser do tipo social e/ou econômico. Diante do papel exercido pelo Estado surgem as necessidades das políticas públicas territoriais, que Costa (2001), as caracterizam da seguinte maneira:

[...] as políticas territoriais têm sido entendidas no âmbito restrito dos planos regionais de desenvolvimento, isto é, enquanto atividade planejadora do Estado voltada ao enfoque regional específico, resultando comumente em projetos especiais que interessam a uma ou outra região específica. No nosso enfoque, entretanto, as políticas territoriais extrapolam essa noção, abrangendo toda e qualquer atividade estatal que implique, simultaneamente, uma dada concepção do espaço nacional, uma estratégia de intervenção ao nível da estrutura territorial e, por fim, mecanismos concretos que sejam capazes de viabilizar essas políticas. (Costa, 2001, p.13)

Entendido que as políticas que possuem estratégias de intervenção com instrumentos da realidade de cada caso são consideradas como territoriais. E por meio disso podem, dependendo de suas características próprias, ser consideradas como relativas ao desenvolvimento regional. Essas políticas regionais, para Amin (2007), não podem se pautar apenas em princípios de competitividade entre as regiões, mas num desenvolvimento associado que haja inserção de todo o território onde as regiões são solidárias e contribuintes umas com as outras.

As disparidades inter-regionais possuem a tendência de se manterem e aumentar continuamente. Logo, o Estado precisa ser ativo na criação e implementação de políticas de desenvolvimento regional.

Tais políticas, devem então, ser de caráter orientador, que priorize superações de disparidades gerados por desenvolvimento desigual, além de guiar o fortalecimento de articulações entre regiões de um mesmo mercado interno. Pensando nesse sentido que mecanismos de políticas públicas como SUDENE, SUDECO, SUDESUL e SUDAM foram elaboradas, para que o desenvolvimento começasse a ser direcionado, para que se pudesse minimizar os efeitos do desenvolvimento que ocorria de forma desigual nas regiões do Brasil. Até então, o planejamento territorial era pensado de forma macrorregional, imaginando-se o território de forma homogênea. (Brito, Mattedi; \& Dos Santos, 2017).

O processo de industrialização do Brasil se iniciou nas localidades, principalmente pela região Sudeste, após a Segunda Guerra Mundial. Regiões como Centro-Oeste, Norte e Nordeste ficaram às margens do processo de industrialização do país. Dados descritos por Furtado (1959) mostram que antes da guerra, 1939, o Nordeste participou na economia brasileira com um produto interno bruto de 30\% e após, 1959, se tratava de apenas 11\%, pois as regiões que se encontravam em processo de industrialização eram as que obtinham maiores crescimento.

Pensando então no processo de crescimento e desenvolvimento menos distinto entre as regiões, em 1959 foi criada a SUDENE, que à medida que o mercado interno era alavancado pela industrialização corrigia e reestruturava questões econômicas e sociais da região. Teve duração de 1959 a 2001. Funcionou como sistema de incentivos fiscais principalmente atraindo capital privado.

Para carvalho (2011) o funcionamento da Sudene foi a seguinte: 
A SUDENE tentou, apesar do processo de desgaste e enfraquecimento por que passou, fazer uma política de caráter desenvolvimentista, que proporcionasse maior inclusão social e diminuição das desigualdades interpessoais e interregionais de renda. Entretanto, apesar de haver conseguido modificar fortemente sua estrutura produtiva, não foi bem sucedida em termos sociais. (Carvalho, 2011, p.287)

Nessa mesma direção de políticas públicas pode ser citada a SUDECO que foi um órgão federal com a finalidade de planejamento e intervenção na região Centro-Oeste. Pode ser entendida como projeto para desenvolvimento regional e nacional, onde se pretendia disseminar o capital monopolista no interior do país. Com essa disseminação era pretendido "PRODUZIR oportunidades e PROMOVER seu aproveitamento para ACELERAR o desenvolvimento harmônico do CentroOeste" (Abreu, 2001, p. 31).

Esse modelo se enquadra no modelo de intervenção desenvolvimentista que Bielschowsky (1996) descreveu como tipo de projeto econômico com principais ideias de industrialização integral para superação da pobreza, onde o Estado define a expansão desejada de determinados setores, e então capta e orienta recursos financeiros para investimento direto nos setores específicos.

Essa intervenção no Centro Oeste se deu principalmente por causa do processo de ocupação ao qual foi submetido. E que até por volta da década de 1970 foi atribuído como vazios demográficos e/ou áreas com destinação apenas a atividades agropecuárias.

A SUDECO foi oficialmente criada pela Lei n. 5.365 de 1967. Suas principais missões seriam coordenar e elaborar planos de desenvolvimento regional. Durante a crise do petróleo, O II Plano Nacional de Desenvolvimento foi elaborado e nela constava a necessidade de inserção maior do Centro Oeste no cenário de crescimento do Brasil, pois nele citava às necessidades de maior produção agrícola e maior poder de absorção do crescimento populacional do país. Nesse sentido a maior ocupação e produção agrícola do centro oeste e da Amazônia se intensificava como chave de desenvolvimento. Como demonstrado no trecho:

Trata-se agora de exigir muito mais da agropecuária [...]. Significa, de um lado, efetivar a vocação do Brasil como supridor mundial de alimentos, matérias-primas agrícolas e produtos agrícolas industrializados [...]. Cabe recordar que o Brasil, no quadro mundial, é um dos poucos países ainda com ampla disponibilidade de espaço. A ocupação de novas áreas deverá continuar, como processo importante de expansão da agropecuária, dada a existência de terras relativamente férteis para deslocamento da fronteira agrícola, tendo em vista que o gigantesco sistema viário já construído, colocou à disposição do setor imensas áreas no Centro-Oeste e na Amazônia. (Brasil, 1974, p. 33)

O Programa trouxe como consequências positivas a modernização no processo de produção agropecuária, principalmente em gêneros alimentícios voltados à exportação. Inseriu-se ao POLOCENTRO que seguia o conceito de Polos de crescimento de François Perroux, que esses seriam áreas para polos de desenvolvimento que disseminariam para regiões vizinhas agriculturas desenvolvidas. (Cavalcante \& Barreira, 2011).

Após fortes reduções de investimentos a SUDECO paralisou seus projetos em 1985. E sua extinção aconteceu em 1990.

Depois da década de 1950 o assunto de desigualdade entre as regiões começou a ser mais debatido, afinal a região Sudeste detinha a concentração de capital do país, privando que outras regiões crescessem na mesma proporção, como já visto anteriormente sendo motivos para efetivação das Superintendências de Desenvolvimento do Nordeste, Centro Oeste e também do Sul com a SUDESUL.

A Superintendência de Desenvolvimento da região Sul (SUDESUL) foi instituída em 1967 pelo decreto lei n. 301. Teve atuação por 23 anos com a finalidade de orientação de planos para desenvolvimento da região,

Atuou principalmente firmando convênios que trouxessem desenvolvimento à região. Recebeu apoio de instituições 
como Organização Mundial da Saúde (OMS), Organização dos Estados Americanos (OEA) e Organização das Nações Unidas para Educação, Ciência e Cultura (UNESCO). Projetos agrícolas e hidrológicos também foram ações efetivas da SUDESUL. (Almeida, Messias \& Goularti Filho, 2010).

Nesse mesmo sentido também foi criada a Superintendência de Desenvolvimento da Amazônia que foi implementada com a finalidade de gerir programas que objetivassem a integração da região no contexto social e econômico brasileiro. Criada pela lei $\mathrm{n}^{\circ} 5.173$, de 27 de outubro de 1966, teve como principais objetivos de coordenar, planejar e promover ações governamentais que fossem destinados ao desenvolvimento da Amazônia, além de induzir ações do setor privado e direcionar atuações de instituições públicas (Brito, 2001)

Outras medidas foram criadas, como o Ministério da Integração Nacional que em 1999 surgiu com a finalidade de reorganizar o Estado no que diz respeito ao resgate de atribuições de formulação e condução de políticas, planos, e programas de desenvolvimento, além de inserção de regiões periféricas no plano de melhorias. Desse ministério surgiram ações específicas para cada caso das Regiões, mais recentemente conhecida como Programa de Sustentabilidade de Espaços SubRegionais (PROMESO); debates a respeito de Políticas Nacionais de Ordenamento Territorial (PNOT); implantação da Política Nacional de Desenvolvimento Regional (PNDR).

A Política Nacional de Desenvolvimento Regional (PNDR) também é instrumento de coordenação e cooperação, tem atuação em todos os níveis de governo e é responsável pela devida superação das desigualdades regionais, onde o país se torne justo aos níveis de territórios e também coeso.

A primeira fase foi instituída pelo decreto 6.047 de 2007. Alves e Rocha Neto (2014), identificam que um dos maiores problemas que influenciaram na necessidade de criação da PNDR foi a ausência que o país teve de políticas públicas no período das décadas de 1980 e 1990, que para Cargnin (2011, p.13), essa problemática se deu desde o fim da década de 1970 onde ele descreve: "o planejamento territorial esteve fora da agenda acadêmica e da centralidade das políticas governamentais brasileiras, tanto no cenário nacional quanto no dos estados".

Os autores, Alves e Rocha Neto (2014), reconhecem a PNDR como a materialização do primeiro esforço do Estado em criar políticas para o desenvolvimento regional. E como características podem ser citadas algumas como:

a) objetivavam-se mudanças de paradigmas a fim de superar abordagens que era macrorregional, mostrando que problemas regionais são em múltiplas escalas geográficas e a atuação deveria ser necessariamente nacional;

b) Passou de abordagem exógena, que até então era do tipo top-down em que as ações são caracterizadas por terem sido de grandes investimentos, porém sem devidos controles sociais, para o tipo bottom-up com controle e participação social;

c) mudou o olhar sobre as regiões, alterando a visão equivocada onde o moderno estava atrelado às regiões mais desenvolvidas e o arcaico às com menor desenvolvimento. Passando então a ver a diversidade regional como ativo que deveria ser explorado economicamente.

A PNDR foi atualizada para sua segunda versão em que aprofundasse no problema da desigualdade a fim de reverter tendências já incorporadas na sociedade e forjadas historicamente. Objetivando a coesão territorial, política e econômica.

Separando quatro objetivos principais da PNDR II podem ser destacados em primeiro a convergência, em que se almeja reduzir diferenças no desenvolvimento e qualidade de vida entre regiões promovendo equidade nas oportunidades de desenvolvimento.

Em segundo é a promoção da competitividade entre regiões com declínio populacional e elevadas taxas de emigração por causa da baixa geração de emprego e renda por serviços. Podendo estas serem de baixa renda ou não.

O terceiro objetivo é a valorização da diversidade econômica em regiões com forte especialização da produção de commodities agrícolas e/ou mineral, que tenham baixo valor agregado em exportações, elevada desigualdade social e baixa diversidade econômica. 
E o último aqui descrito é o fortalecimento da rede de cidades médias, pois uma rede de cidades com mais harmonia entre os níveis hierárquicos com a identificação e fortalecimento das centralidades em diversas escalas, contribui para a interiorização do desenvolvimento.

$\mathrm{Na}$ análise de Carniello e Santos (2021) a PNDR conceitua que desenvolvimento tem foco na qualidade de vida da população, porém com centralidade na economia, pois trata que a redução das desigualdades econômicas e sociais resulta em crescimento econômico.

As políticas de Desenvolvimento são instrumentos que rejeitam os preceitos Neoliberais, sendo então características de intervenção do Estado para o equilíbrio da balança, buscando crescimento econômico e desenvolvimento nacional com distribuição mais igualitária (Cardozo \& Martins, 2020)

Como já evidenciado por Theis (2019), uma medida para combater as disparidades regionais é a intervenção do Estado:

O diagnóstico é de que o mercado autorregulado é uma ficção; deixando-se que funcione sem coordenação, inevitavelmente, produzirá desigualdades. Portanto, há dois pontos a considerar: é preciso (a) corrigir as desigualdades e (b) regular o mercado que as produz. (...) Assim, a presença do Estado, este agente incumbido de coordenar o mercado, atenuaria a geração de desigualdades sócio-espaciais (Theis, 2019, p.354).

Ao que se entende até aqui, políticas de Desenvolvimento são instrumentos que rejeitam os preceitos Neoliberais, sendo então características de intervenção do Estado para o equilíbrio da balança, buscando crescimento econômico e desenvolvimento nacional com distribuição mais igualitária. (Cardozo \& Martins, 2020).

\section{Considerações Finais}

Tendo mostrado parte teórica conceitual de políticas públicas, desenvolvimento, região, desenvolvimento regional e local para maior entendimento da importância de intervenção do Estado a fim de promover desenvolvimento baseado em crescimento econômico e preocupação social, pode-se concluir que:

O que pode ser destacado é que as políticas públicas de desenvolvimento surgiram principalmente por causa de problemas sociais, foram originadas pelo Estado. As políticas públicas são formas de garantir que a sociedade tenha seus direitos garantidos, por meio de intervenção do Estado.

Políticas públicas são todas as ações, metas e planos traçados pelo governo (nacional, estadual ou municipal) para alcançar o bem-estar social e o interesse público. Na verdade, as ações escolhidas pelos funcionários públicos (funcionários do governo ou tomadores de decisão) são aquelas que eles entendem como demandas ou expectativas da sociedade. Em outras palavras, o bem-estar social é sempre definido pelo governo e não pela sociedade, afinal o berço do capitalismo e da economia globalizada tende a disseminar a disparidade.

Atuações do Estado, como a condução da PNDR no Brasil teve embasamento na necessidade de desenvolvimento econômico com desenvolvimento social. Esses critérios ganharam força nas últimas décadas depois do fim das Superintendências que também tiveram o mesmo cunho. Essas ações mostram a necessidade de intervenção do Estado para o bem estar da sociedade que embasada na economia globalizada e capitalista tende a promover a desigualdade entre as regiões. Este artigo da base para que os estudos sobre políticas públicas no Brasil continuem, principalmente com analises mais quantitativas para verificar as interferências que elas têm no desenvolvimento do país. 


\section{Referências}

Abreu, S. de. (2001). Planejamento governamental: a SUDECO no" Espaço Mato-Grossense". Contexto, propósitos e contradições. Tese de Doutorado. Universidade de São Paulo.

Almeida, A. S., Messias T. A. \& Goulart Filho, A. (2010). A trajetória da SUDESUL e as políticas de desenvolvimento regional para Santa Catarina 19671990. UFRGS.

Alves, A. M., Rocha Neto, J. M. (2014). A Nova Política de Desenvolvimento Regional - PNDR II. Revista Política e Planejamento Regional (RPPR), 1(2), 311-338.

Bellingieri, J. C. (2017). Teorias do desenvolvimento regional e local: uma revisão bibliográfica. RDE - Revista de Desenvolvimento Econômico, 2(37), 6-34. Brasil (1974). II Plano Nacional de Desenvolvimento (PND). Brasília: Imprensa Oficial.

Brito, D. C. de. (2001) A SUDAM e a crise da modernização forçada: reforma do estado e sustentabilidade na Amazônia. Revista Ambiente e Sociedade, 8, 6990 .

Brito, V. C, Mattedi, M. A. \& Dos Santos, G. F. (2017). O uso de múltiplas escalas geográficas no planejamento do desenvolvimento regional. Revista Política e Planejamento Regional, 4(1), 1-30.

Cardozo, S. A \& Martins, H. (2020). New Developmentalism, Public Policies, and Regional. Inequalities in Brazil: The Advances and Limitations of Lula's and Dilma's Governments. Revista Latin American Perspectives. 47(2), 147-162.

Carniello, M. F.\& Santos, M. J. dos. (2021) Comunicação para o desenvolvimento territorial: análise da Política Nacional de Desenvolvimento Regional. Revista Redes, 26, 1-19.

Corrêa, J. C. S., Silveira, R. L. L.\& Kist, R. B. B. (2019). Sobre o conceito de desenvolvimento regional: notas para debate. Revista Brasileira de Gestão e Desenvolvimento Regional, 15(7), 3-15.

Cargnin, A. P. (2011). Políticas de desenvolvimento regional no Rio Grande do Sul: vestígios, marcas e repercussões territoriais. Tese de Doutorado UFRGS/PPGGEA. 318 p.

Carvalho, F. F. (2011) Sudene: do desenvolvimento cepalino ao desenvolvimento endógeno. In: Amaral Filho, J. do e Carrillo, J. (coords). Trajetórias de desenvolvimento local e regional: uma comparação entre a região nordeste do Brasil e a Baixa Califórnia (México). E-papers, p.287-308.

Castro, J. A. de \& Oliveira, M. G. de. (2014). Políticas públicas e desenvolvimento. In: MADEIRA, L. M. (Org.). Avaliação de Políticas Públicas. 20-48.

Cavalcante, L. R. (2018). Políticas de Desenvolvimento Regional no Brasil: uma estimativa de custos. Revista Brasileira de Gestão e Desenvolvimento Regional, 14(3), 147-171.

Cavalcante, M. A. \& Barreira, C. C. M. A. (2011). Ações da SUDECO no Desenvolvimento.do Centro-Oeste no Estado de Goiás. Revista Boletim Goiano de Geografia. 31(2), 179-191.

Dallabrida, V. R. (2010). Desenvolvimento regional: Porque algumas regiões se desenvolvem e outras não. Ed. EDUNISC.

de Andrade Carneiro, L., Rodrigues, W., França, G., \& Prata, D. N. (2020). Uso de tecnologias no ensino superior público brasileiro em tempos de pandemia COVID-19. Research, Society and Development, 9(8), e267985485-e267985485.

Lefebvre, H. (1991). The production of space. Basil Blackwell.

Furtado, C. A. (1959). Operação Nordeste. MEC, ISEB.

Furtado, C. (1961). Desenvolvimento e subdesenvolvimento. Editora Fundo de Cultura

Furtado, C. (1999). O longo amanhecer: reflexões sobre a formação do Brasil. Paz e Terra.

Gil, A. C. (2008). Métodos e técnicas de pesquisa social. (6a ed.), Editora Atlas SA.

Haesbaert, R. (2005) “Região: trajetos e perspectivas”. Anais da I Jornada de Economia Regional Comparada. FEE-RS. 1-15.

Haesbaert, R. (2010). Regional-global: dilemas da região e da regionalização na geografia contemporânea. Bertrand Brasil

Harvey, D. (1993). Condição Pós-Moderna. Loyola 349 p

Harvey, D. (1973). Social justice and the city. London: Edward Arnold.

Milone, P. C. (1998). Crescimento e desenvolvimento econômico: teorias e evidências empíricas. Montoro Filho, A. F. et al. Manual de economia. São Paulo: Saraiva. 511-524

Oliveira, A. G. de, Silva, C. L.\& Lovato, E. L. (2014). Desenvolvimento local: conceitos e metodologias - políticas públicas de desenvolvimento rural e urbano. Revista Orbis Latina, 4, 110-123.

Oliveira, F. de. (1981). Elegia para uma re(li)gião. (3a ed.), Paz e Terra.

Oliveira, G. B. (2002). Uma discussão sobre o conceito de desenvolvimento. Revista FAE, 5(2), 37-48. 
Research, Society and Development, v. 10, n. 10, e235101018757, 2021

(CC BY 4.0) | ISSN 2525-3409 | DOI: http://dx.doi.org/10.33448/rsd-v10i10.18757

Pozenato, J. C. (2001). Algumas considerações sobre região e regionalidade. Filosofia: diálogo de horizontes. 589-591.

Reyes, G. E. (2001). Four main theories of development: modernization, dependency, word-system and globalization. Nómadas. Revista Crítica de Ciencias Sociales y Jurídicas. 4(2), 109-124.

Theis, I. M. (2019). O que é desenvolvimento Regional? Uma aproximação a partir da realidade brasileira. Revista Redes, 24(3), 334-360. 